\title{
Preventive and improvement effects of exercise training and supplement intake in white adipose tissues on obesity and lifestyle-related diseases
}

\author{
Takuya Sakurai · Junetsu Ogasawara Takako Kizaki $\cdot$ Yoshinaga Ishibashi · \\ Yoshikazu Sumitani $\cdot$ Kazuto Takahashi $\cdot$ Hitoshi Ishida $\cdot$ Hiromi Miyazaki \\ Daizoh Saitoh $\cdot$ Shukoh Haga $\cdot$ Tetsuya Izawa $\cdot$ Hideki Ohno
}

Received: 6 October 2011/ Accepted: 5 February 2012/Published online: 24 February 2012

(C) The Japanese Society for Hygiene 2012

\begin{abstract}
Recent increases in the number of obese individuals and individuals suffering from lifestyle-related diseases, such as type 2 diabetes, that accompany obesity have become a serious social problem. White adipose tissue (WAT) is more than a mere organ for storage of energy; it is also a highly active metabolic and endocrine organ that secretes physiologically active substances collectively known as adipokines, including tumor necrosis factor- $\alpha$ and adiponectin. Dysregulated expression of adipokines in WAT that is hypertrophied by obesity has been closely associated with the phenomenon of insulin resistance. Therefore, WAT is currently considered to be one of the tissues that promote lifestyle-related diseases. Reduction of excess WAT that results from obesity is seen as an
\end{abstract}

T. Sakurai $(\bowtie)$ · J. Ogasawara · T. Kizaki · Y. Ishibashi · H. Ohno

Department of Molecular Predictive Medicine and Sport

Science, School of Medicine, Kyorin University,

6-20-2, Shinkawa, Mitaka, Tokyo 181-8611, Japan

e-mail: sakutaku@ks.kyorin-u.ac.jp

Y. Sumitani $\cdot$ K. Takahashi $\cdot$ H. Ishida

Third Department of Internal Medicine,

School of Medicine, Kyorin University,

6-20-2, Shinkawa, Mitaka, Tokyo 181-8611, Japan

H. Miyazaki · D. Saitoh

Division of Traumatology,

National Defense Medical College Research Institute,

3-2, Namiki, Tokorozara, Saitama 359-8513, Japan

S. Haga

University of Tsukuba, 1-1-1, Tennodai,

Tsukuba, Ibaraki 305-8577, Japan

T. Izawa

Faculty of Health and Sport Science, Doshisha University, 1-3, Tatara Miyakodani, Kyotanabe, Kyoto 610-0394, Japan important strategy in preventing and improving lifestylerelated diseases. This review shows that exercise training as well as intake of supplements, such as polyphenols, is one strategy for this, because this regimen can result in reduction of WAT mass, which affects the expression and secretory response of adipokines.

Keywords Exercise training - Polyphenol - White adipose tissue $\cdot$ Obesity $\cdot$ Lifestyle-related diseases

\section{Introduction}

Recent changes in human lifestyles, including high-calorie diets and a lack of physical exercise, have resulted in increases in the occurrence of obesity [1]. Obesity increases the risk of so-called lifestyle-related diseases such as type 2 diabetes and hyperlipidemia, and it is widely known that obesity and type 2 diabetes are responsible for arteriosclerosis $[2,3]$. Therefore, strategies for prevention and improvement of obesity and lifestyle-related diseases are thought to be an extremely important public health issue.

Many epidemiological studies have shown the preventive effects of exercise training (TR) and dietary supplements, including polyphenols, on obesity and lifestyle-related diseases; For example, Helmrich et al. [4] tracked 5,990 male alumni of the University of Pennsylvania and found that, for each $500 \mathrm{kcal}$ increase in energy expenditure during exercise per week, the risk of developing type 2 diabetes decreased by $6 \%$. Another study on 21,271 male physicians in the USA over 5 years demonstrated that the group that exercised to the point of breaking into a sweat once per week had a lower risk of developing diabetes [5]. On the other hand, regarding intake of polyphenols, such as catechin and procyanidin, subjects who 


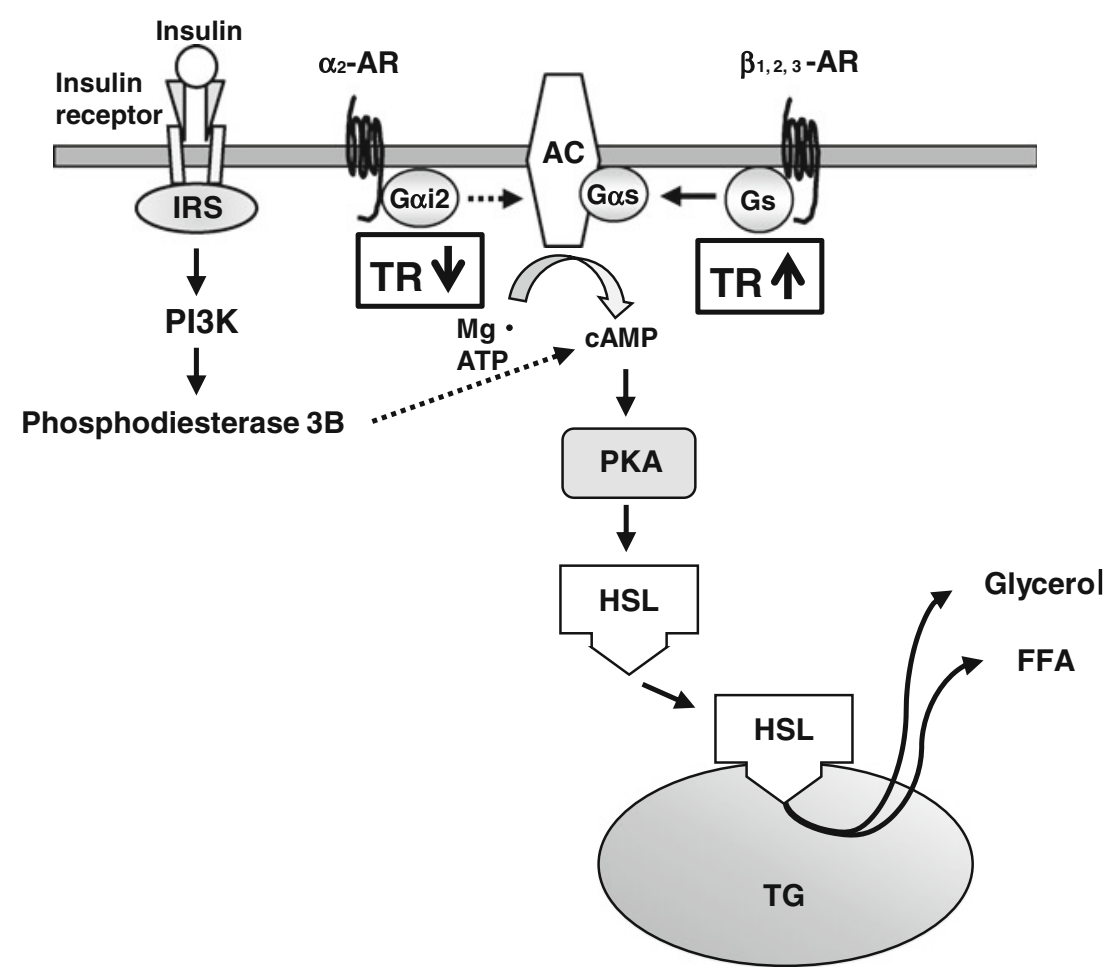

Fig. 1 Effects of exercise training on the adrenergic receptormediated, adipocyte lipolytic response. When $\beta$-adrenergic receptor $(\beta$-AR) binds to an agonist and associates with a stimulatory $\mathrm{G}$ protein (Gs), adenylate cyclase (AC) is activated by Gs $\alpha$ subunit $(\mathrm{G} \alpha \mathrm{s})$ and cyclic AMP (cAMP) is produced. cAMP stimulates cAMPdependent kinase (PKA), and hormone-sensitive lipase (HSL) is phosphorylated and activated. The activated HSL hydrolyzes triglycerides (TG). On the contrary, TG degradation is suppressed by the

maintained habitual catechin-rich tea consumption for more than 10 years reportedly had a lower percentage of body fat and a lower waist-to-hip ratio than consumers who did not [6]. Moreover, a Netherlands cohort study of 4,280 adults showed an inverse relationship between polyphenol intake over a 14-year period and body mass index (BMI) increase [7], although BMI varied only slightly with green tea consumption in 2 Japanese epidemiological studies in which a negative association was observed between tea consumption and serum levels of total cholesterol $[8,9]$. In addition, the fact that polyphenols have powerful antioxidative effects implies that they would be effective in reducing cardiovascular diseases [10, 11]. Reportedly, polyphenols also inhibit the oxidation of low-density lipoprotein, identified as a leading cause of arteriosclerosis [12-14].

The main role of subcutaneous and visceral white adipose tissue (WAT) is supply and storage of energy, which is carried out by adipocytes within the tissue. Much of the ingested excess energy is stored within adipocytes in the form of triglycerides consisting of fatty acids bonded to glycerol. During exercise, triglycerides within adipocytes inhibition of cAMP production by $\alpha_{2}$-AR through the inhibitory $G$ protein $\alpha$ subunit $(\mathrm{G} \alpha \mathrm{i})$. Insulin inhibits the lipolytic response via downregulation of cAMP production by activated phosphodiesterase 3B. Exercise training (TR) increases the association efficiency of the $\beta$-AR and $\mathrm{Gs}$, and leads to a reduction in the amount of Gi protein. As a result, sensitivity and reactivity to $\beta$-AR agonists increase. FFA free fatty acid, IRS insulin receptor substrate, PI3K phosphatidylinositol-3 kinase

are broken down due to the secretion of catecholamines (adrenaline and noradrenaline) from the adrenal medulla and sympathetic nerve peripheries, and the resultant fatty acids are transported to tissues such as skeletal muscle (Fig. 1) [15]. However, apart from adipose tissues supplying and storing energy, they also secrete various humoral factors called "adipokines" that are actively involved in metabolic reactions. The dysregulated expression of adipokines due to obesity is known to be closely related to the onset of lifestyle-related diseases [16-18]. Therefore, WAT is considered to be very important as one of the tissues that cause lifestyle-related diseases.

This article reviews the effect of TR and the intake of polyphenols on WAT mass and the expression of adipokines in WAT.

\section{The effect of TR in reducing the amount of WAT}

TR is widely known to reduce the weight of subcutaneous and visceral WAT in experimental animals and humans. A dose-response relationship has been observed between 
the amount of TR and the amount of WAT mass reduction; that is, relatively vigorous exercise produces a greater effect [19]. However, detailed mechanisms that regulate the dose-response relationship with exercise are not well understood.

One of the reasons for a TR-induced reduction in WAT mass might be hypotrophy of mature adipocytes [20-26], which has been associated with greater adipocyte lipolysis in exercise-trained subjects than in sedentary controls $[27,28]$. TR increases the association efficiency of the $\beta$-adrenergic receptor $(\beta-\mathrm{AR})$ and stimulatory $\mathrm{G}$ protein, and decreases the amount of inhibitory $G$ protein in the lipolytic response under the influence of catecholamines (Fig. 1) [29, 30]. Therefore, sensitivity and reactivity to $\beta$-AR agonists increase. However, the results of the effects of TR on the number of adipocytes contained in WAT are controversial. Some studies, including ours, have shown that WAT in exercise-trained rodents contains significantly fewer cells than that in sedentary controls [21, 22, 26] or tends to do so [20], but some have found no significant difference in adipocyte numbers [23-25]. The difference in the starting age for TR appears to influence the effects of TR on adipocyte numbers, because when TR was started at a very early stage of a rat's life (0.7-1.1 weeks of age), it reduced both adipocyte number and size; however, when TR was started at 9-27 weeks of age, only adipocyte size was reduced [21-24]. In fact, in our study, the starting age of the rats (5 weeks old), corresponding to childhood, was thought to be important for the reduction of adipocyte numbers by TR [26]. Nevertheless, additional research is necessary, because reports state that, even when TR is started at 5 weeks of age, it does not affect adipocyte number [25]. The TR-induced reduction in the number of adipocytes appeared not to be due to apoptosis of mature adipocytes, but rather to suppressed adipocyte differentiation of stromal-vascular fraction (SVF) cells containing adipose tissue-derived stem cells (ADSC), which are present in WAT for differentiation into adipocytes, vascular endothelial cells, and the like [26, 31, 32]. Some of the possible mechanisms for the TR-induced inhibition of adipogenesis may be enhanced expression of pre-adipocyte factor-1, which inhibits adipocyte differentiation [33], and decreased expression of peroxisome proliferator-activated receptor $\gamma$, the master regulator of adipocyte differentiation [34, 35], through upregulation of the protein level of hypoxia-inducible factor- $1 \alpha$, which is also reported to inhibit adipogenesis [36], in SVF cells [26] (Fig. 2). Unlike the case of adipocyte differentiation, the ability of SVF cells containing ADSC to differentiate into vascular endothelial cells appears to be retained after TR [37] (Fig. 2).

\section{Efficacy of polyphenol intake in reducing WAT mass}

In recent years, procyanidin has been reported to increase the lipolytic response and has been found to possess fatburning effects [38]. We have also found that lycheederived polyphenol stimulates the lipolytic response in isolated adipocytes from rats through activation of

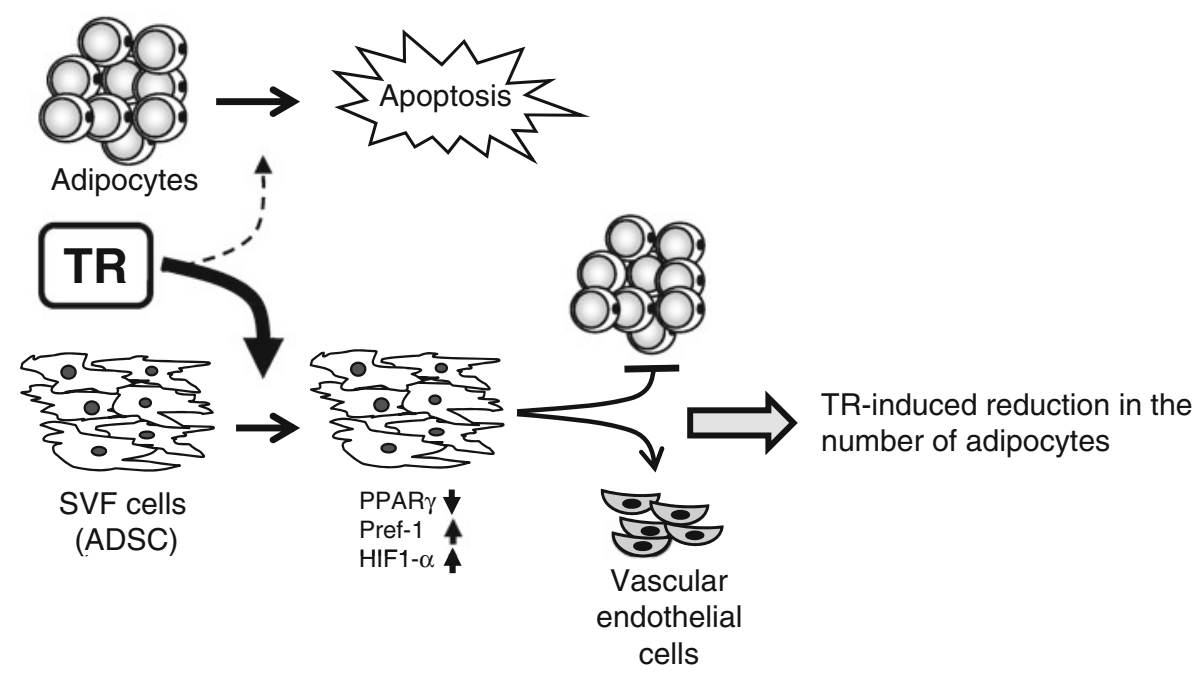

Fig. 2 Schematic model for a proposed mechanism of TR-induced reduction of adipocyte numbers in white adipose tissue. TR suppresses adipocyte differentiation of stromal-vascular fraction (SVF) cells containing adipose tissue-derived stem cells (ADSC) in white adipose tissue (WAT). Possible mechanisms for the TRinduced inhibition of adipogenesis may be enhanced expression of pre-adipocyte factor-1 (Pref-1), and decreased expression of peroxisome proliferator-activated receptor $\gamma(\operatorname{PPAR} \gamma)$, through upregulation of the hypoxia-inducible factor- $1 \alpha$ (HIF-1 $\alpha$ ) level in SVF cells. However, the ability of SVF cells containing ADSC to differentiate into vascular endothelial cells is retained after TR 
Fig. 3 Model of the development of chronic inflammation in WAT. Adipocytes begin to grow as a result of factors such as excess energy intake and lack of exercise, and MCP-1 is secreted from these enlarged cells. Macrophages infiltrate into WAT by the action of MCP-1, and as a result, increased expression of inflammatory adipokines [TNF- $\alpha, \mathrm{MCP}-1$, and interleukin-6 (IL-6)] and decreased expression of antiinflammatory adipokines

(adiponectin) occur in WAT

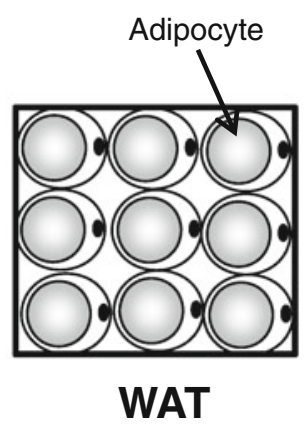

extracellular signal-regulated kinase [39-41]. There are also reports that polyphenols inhibit adipogenesis [42-44]. This is reflected in animal studies where polyphenol intake seems to inhibit the increase of WAT that results from a high-fat diet (HFD) [43-45]. However, as catechin is reported to promote adipocyte differentiation in human bone marrow mesenchymal cells [46], the effect of polyphenols on the differentiation of adipocytes remains debatable. Regarding the effects of polyphenol intake on exercise, combining TR with intake of catechin-laden tea extract in animal studies seems to additively inhibit HFD-induced obesity, increase the duration of endurance exercise, and increase the utilization of lipids [47]. Furthermore, there are reports that have confirmed an increased lipid oxidation rate in humans during exercise with the intake of tea extract [48].

\section{The influence of TR on the WAT inflammatory response}

Recently, obesity has been closely associated with lowgrade chronic inflammatory response [16-18]. Indeed, an increased number of infiltrating macrophages and dysregulated expression of some inflammation-related adipokines, such as tumor necrosis factor- $\alpha$ (TNF- $\alpha)$ and monocyte chemoattractant protein-1 (MCP-1), have been observed in the WAT of obese mice [49-51]. Adipose TNF- $\alpha$ expression in genetically obese (ob/ob) mice and obese patients is increased [51,52] along with the secretion of TNF- $\alpha$, which induces insulin resistance in skeletal muscles and adipocytes [53-55]. In addition, expression of the gene for MCP-1 is upregulated in the WAT of ob/ob mice and HFD-induced obese mice, and overexpression of MCP-1 in adipocytes promotes macrophage infiltration in WAT $[56,57]$. On the other hand, decreased levels of adiponectin in addition to decreased expression of the gene for adiponectin in WAT have been observed in the plasma

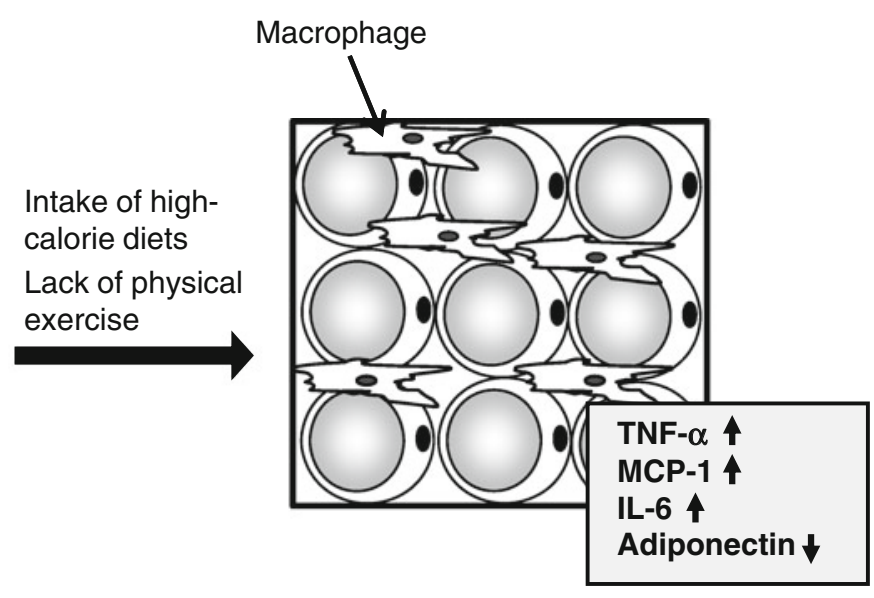

of obese patients $[58,59]$. Because adiponectin induces fatty acid oxidation and decreases the concentration of triglycerides in skeletal muscle and liver, reduction of adiponectin levels is implicated in the onset of type 2 diabetes $[60,61]$.

This section mainly describes the effect of TR on the expression of representative adipokines in WAT (Fig. 3).

\section{TNF- $\alpha$}

The effect of TR on the expression of TNF- $\alpha$ in WAT is controversial; For example, the increased expression of the gene for TNF- $\alpha$ in the mesenteric visceral WAT of HFDinduced obese mice is reported to have been inhibited by self-propelled running exercise in a rotating cage over a period of 6 weeks [62]. Furthermore, in a similar report combining HFD with TR by treadmill running, there was no difference in TNF- $\alpha$ gene expression in visceral WAT between the HFD group that continued TR for 6 weeks and the group with HFD alone. After a further 6 weeks, however, the increased expression of the gene for TNF- $\alpha$ due to HFD was attenuated by TR [63]. We have reported a decrease in the TNF- $\alpha$ protein content in the epididymal WAT of lean rats as a result of treadmill running for 9 weeks [31, 64]. In contrast, Nara et al. [65] subjected mice to the combination of a high-sucrose diet and TR that consisted of self-propelled running, and reported an increase in TNF- $\alpha$ gene and protein expression in mesenteric visceral WAT in comparison with a group that had only a high-sucrose diet. Recently, Lira et al. [66] observed an increased amount of TNF- $\alpha$ in the mesenteric visceral WAT of rats subjected to 8 weeks of treadmill TR. In addition to these animal studies, decreased TNF- $\alpha$ gene expression has been observed in investigations of subcutaneous WAT in morbidly obese humans with average BMI of $45.8 \mathrm{~kg} / \mathrm{m}^{2}$ who underwent a combination of dietary therapy and TR such as walking 5 times a week for 15 weeks [67]. However, in another study, no change in 
expression of the gene for TNF- $\alpha$ was observed in the subcutaneous WAT of obese adults even when body mass and body fat were reduced after 12 weeks of aerobic exercise [68].

\section{$\mathrm{MCP}-1$}

Similar to TNF- $\alpha$, conflicting results have been obtained with regards to MCP-1. An increase in the gene expression of visceral WAT in mice with obesity caused by HFD was reportedly inhibited by TR that consisted of running [62, 63]. We have observed a decrease in MCP-1 protein content in epididymal, retroperitoneal, and subcutaneous WAT of lean rats as a result of treadmill running for 9 weeks [64]. Nevertheless, in other studies, changes in MCP-1 gene expression were observed neither in the subcutaneous or visceral WAT in rats subjected to 4 weeks of self-propelled running exercise, nor in the subcutaneous WAT of obese humans subjected to 12 weeks of aerobic exercise [68, 69]. In addition, there are also cases in which no significant change in MCP-1 gene expression was seen in WAT as a result of TR despite a decrease in TNF- $\alpha$ gene expression [67].

\section{Adiponectin}

Increased expression of the gene for adiponectin was observed in the subcutaneous WAT of obese patients who underwent a combination of dietary therapy and TR such as walking 5 times a week for 15 weeks [67] or aerobic exercise for 12 weeks [68]. However, no effect of TR on adiponectin gene expression in subcutaneous WAT was observed in an examination of obese women who were subjected to exercise on an exercise bike 5 times a week for 12 weeks despite a reduction in body fat [70]. We observed an increased expression of the gene for adiponectin in the visceral and subcutaneous adipocytes of rats as a result of 9 weeks of treadmill running [71]. Unexpectedly, Gollisch et al. [69] reported that short-term (4 weeks) TR by self-propelled running inhibits HFDinduced upregulation of the adiponectin gene expression in the subcutaneous WAT of rats. Interestingly, in the present study, no effect of TR on expression of the gene for adiponectin in visceral WAT was observed.

The effect of TR on macrophage infiltration into adipose tissue

Macrophage infiltration has been examined by macrophage marker gene expression in WAT. In a study of mice subjected to HFD and TR by treadmill running for 16 weeks, Kawanishi et al. [72] reported that the increased expression of the macrophage marker F4/80 gene observed in the group with HFD alone was attenuated by TR. Moreover, decreased gene expression of CD68 and CD14, also macrophage markers, as a result of a 15-week combination of TR and dietary therapy has also been observed in human studies [67]. Nevertheless, in another study, no changes in the expression of genes for CD68 and CD14 were observed in the subcutaneous WAT of obese humans subjected to 12 weeks of aerobic exercise [68].

As explained above, conclusions have not necessarily been reached regarding the influence of TR on the expression of adipokines in WAT. Therefore, further studies are required.

\section{The effect of polyphenol intake on the WAT inflammatory response}

Animal and human studies have shown that the intake of polyphenols improves insulin sensitivity [73-75]. To clarify the reason for this, the effects of polyphenols on the dysregulated expression of inflammation-related adipokines in the WAT of obese animals and humans are being examined. The intake of acacia-derived polyphenols by diabetic-model KKAy mice subjected to HFD suppressed the increase of visceral WAT mass and the dysregulated expression of TNF- $\alpha$ and adiponectin in epididymal WAT [76]. Similarly, we have also reported an attenuation of the increase in epididymal WAT mass and the abnormal expression of inflammation-related adipokines (TNF- $\alpha$ and MCP-1) in mice with the intake of lychee-derived polyphenols [44]. Recently, tests where adipocytes and macrophages were co-cultured have suggested that an increase in TNF- $\alpha$ in the WAT of obese mice is a result of increased expression of TNF- $\alpha$ in infiltrated macrophages rather than in adipocytes [77]. We have shown that grape seed-derived polyphenols attenuate the increase in TNF- $\alpha$ and MCP-1 resulting from this interaction with adipocytes and macrophages [78]. A mechanism for the increased expression of adiponectin from polyphenols has also been identified; For example, when resveratrol, a type of polyphenol, is added to 3T3-L1 adipocytes, the expression of adiponectin increases with signaling through AMP-activated protein kinase and Akt/forkhead transcription factor 1 [79]. However, further studies are required, since no improvements in the features of metabolic syndrome and no changes in serum adiponectin values have been observed by green tea/ green tea extract intake in studies targeting the obese [80].

\section{Is the effect of TR on adipokines a result of the decrease in the amount of WAT?}

Some studies have found that the expression of adipokines is closely associated with adipocyte size; For example, Skurk et al. [81] separated human adipocytes according to 


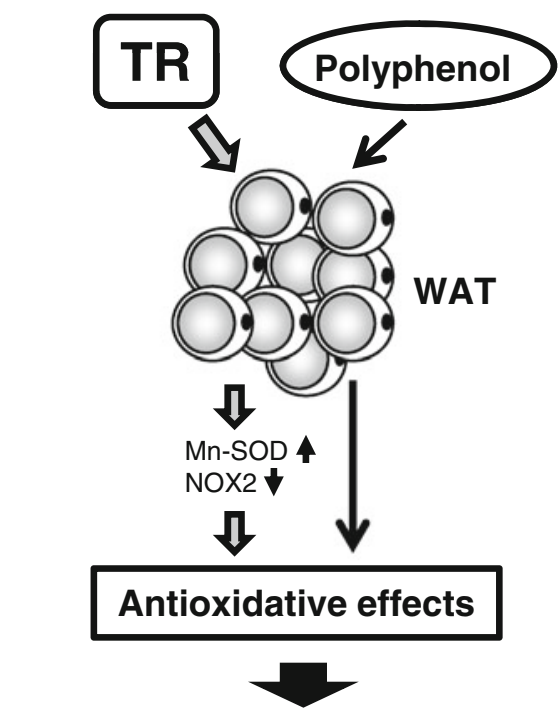

Attenuation of dysregulated inflammation-related adipokine expression

\section{Anti-inflammatory effects}

Fig. 4 Schematic model for the antioxidative/anti-inflammatory effects of TR and polyphenol intake in WAT. TR and polyphenol intake are thought to provide decreased expression of inflammationrelated adipokines through reduction of oxidative stress in WAT. Mn$S O D$ manganese-containing superoxide dismutase, NOX2 nicotinamide adenine dinucleotide phosphate oxidase 2

their volume, and investigated the relationship between adipocyte size and adipokine secretion. As a result, adipocyte size showed a positive correlation with the ability to secrete some adipokines, including leptin, interleukin-6, and MCP-1. Therefore, one of the main reasons for TRinduced change in adipokine production is thought to be a reduction in adipocyte size. However, as for adipokine production, it is unclear whether TR has effects other than the reduction of adipocyte size.

Adipocytes have been shown to be reactive oxygen species (ROS) producing cells, and the increased oxidative stress in WAT resulting from obesity is suggested to be one of the causes for the dysregulated expression of inflammation-related adipokines [82]. We have observed that TR decreases oxidative stress in visceral WAT through enhanced protein expression of the antioxidant enzyme manganese-containing superoxide dismutase and reduced protein expression of the nicotinamide adenine dinucleotide phosphate (NADPH) oxidase 2 (NOX2) [31, 64]. There are many reports that acute exercise enhances the generation of ROS, and that TR establishes a defense system against oxidative stress in various tissues [83, 84]. Therefore, we propose that the adaptation caused by exposure to oxidative stress that is generated during exercise-TR-induced enhancement of the antioxidant defense system in WATdiminishes oxidative stress, which is another reason for attenuation of the dysregulated expression of inflammationrelated adipokines (Fig. 4). Furthermore, as the intake of polyphenols attenuates the abnormal expression of inflammation-related adipokines and increased oxidative stress in WAT resulting from HFD [44] (Fig. 4), the combination of TR and polyphenol intake can be an effective tool that suppresses the adipose tissue inflammatory response.

\section{Conclusions}

Due to differences in the results experienced by experimental subjects, the effects of TR and polyphenol intake on WAT are not consistent among reports found in the literature. On balance, however, the influence is considered to be positive; thus, the synergistic effects of TR and polyphenol intake as preventive and improvement tools for obesity and lifestyle-related diseases will probably grow in importance.

Acknowledgments This work was partially supported by Grants-inAid for Specific Project Research from the Ministry of Education, Culture, Sport, Science, and Technology of Japan. We are also grateful for financial support from the Nakatomi Foundation, Tokyo, Japan, and all contributors.

Conflict of interest We do not have any conflict of interest.

\section{References}

1. Rössner S. Obesity: the disease of the twenty-first century. Int $\mathbf{J}$ Obes Relat Metab Disord. 2002;26:S2-4.

2. Miranda PJ, DeFronzo RA, Califf RM, Guyton JR. Metabolic syndrome: definition, pathophysiology, and mechanisms. Am Heart J. 2005; 149:33-45.

3. Wellen KE, Hotamisligil GS. Inflammation, stress, and diabetes. J Clin Invest. 2005;115:1111-9.

4. Helmrich SP, Ragland DR, Leung RW, Paffenbarger RS Jr. Physical activity and reduced occurrence of non-insulin-dependent diabetes mellitus. N Engl J Med. 1991;325:147-52.

5. Manson JE, Nathan DM, Krolewski AS, Stampfer MJ, Willett WC, Hennekens $\mathrm{CH}$. A prospective study of exercise and incidence of diabetes among US male physicians. JAMA. 1992;268: 63-7.

6. Wu CH, Lu FH, Chang CS, Chang TC, Wang RH, Chang CJ. Relationship among habitual tea consumption, percent body fat, and body fat distribution. Obes Res. 2003;11:1088-95.

7. Hughes LA, Arts IC, Ambergen T, Brants HA, Dagnelie PC, Goldbohm RA, et al. Higher dietary flavone, flavonol, and catechin intakes are associated with less of an increase in BMI over time in women: a longitudinal analysis from the Netherlands Cohort Study. Am J Clin Nutr. 2008;88:1341-52.

8. Kono S, Shinchi K, Wakabayashi K, Honjo S, Todoroki I, Sakurai $\mathrm{Y}$, et al. Relation of green tea consumption to serum lipids and lipoproteins in Japanese men. J Epidemiol. 1996;6:128-33.

9. Tokunaga S, White IR, Frost C, Tanaka K, Kono S, Tokudome S, et al. Green tea consumption and serum lipids and lipoproteins in 
a population of healthy workers in Japan. Ann Epidemiol. 2002;12:157-65.

10. Stoclet JC, Chataigneau T, Ndiaye M, Oak MH, El Bedoui J, Chataigneau $\mathrm{M}$, et al. Vascular protection by dietary polyphenols. Eur J Pharmacol. 2004;500:299-313.

11. Vita JA. Polyphenols and cardiovascular disease: effects on endothelial and platelet function. Am J Clin Nutr. 2005;81:292S$7 \mathrm{~S}$.

12. Mangiapane H, Thomson J, Salter A, Brown S, Bell GD, White DA. The inhibition of the oxidation of low density lipoprotein by (+)-catechin, a naturally occurring flavonoid. Biochem Pharmacol. 1992;43:445-50.

13. Aviram M. Modified forms of low density lipoprotein and atherogenesis. Atherosclerosis. 1993;98:1-9.

14. Hayek T, Fuhrman B, Vaya J, Rosenblat M, Belinky P, Coleman $\mathrm{R}$, et al. Reduced progression of atherosclerosis in apolipoprotein E-deficient mice following consumption of red wine, or its polyphenols quercetin or catechin, is associated with reduced susceptibility of LDL to oxidation and aggregation. Arterioscler Thromb Vasc Biol. 1997; 17:2744-52.

15. Horowitz JF. Fatty acid mobilization from adipose tissue during exercise. Trends Endocrinol Metab. 2003;14:386-92.

16. Tilg H, Moschen AR. Adipocytokines: mediators linking adipose tissue, inflammation and immunity. Nat Rev Immunol. 2006;10: 772-83.

17. Rabe K, Lehrke M, Parhofer KG, Broedl UC. Adipokines and insulin resistance. Mol Med. 2008;14:741-51.

18. Lumeng CN, Saltiel AR. Inflammatory links between obesity and metabolic disease. J Clin Invest. 2011;121:2111-7.

19. Slentz CA, Houmard JA, Kraus WE. Exercise, abdominal obesity, skeletal muscle, and metabolic risk: evidence for a dose response. Obesity (Silver Spring). 2009;17(Suppl 3):S27-33.

20. Askew EW, Huston RL, Plopper CG, Hecker AL. Adipose tissue cellularity and lipolysis. Response to exercise and cortisol treatment. J Clin Invest. 1975;56:521-9.

21. Oscai LB, Spirakis CN, Wolff CA, Beck RJ. Effects of exercise and of food restriction on adipose tissue cellularity. J Lipid Res. 1972;13:588-92.

22. Oscai LB, Babirak SP, Dubach FB, McGarr JA, Spirakis CN. Exercise or food restriction: effect on adipose tissue cellularity. Am J Physiol. 1974;227:901-4.

23. Owens JL, Fuller EO, Nutter DO, DiGirolamo M. Influence of moderate exercise on adipocyte metabolism and hormonal responsiveness. J Appl Physiol. 1977;43:425-30.

24. Bukowiecki L, Lupien J, Follea N, Paradis A, Richard D, LeBlanc J. Mechanism of enhanced lipolysis in adipose tissue of exercise-trained rats. Am J Physiol. 1980;239:E422-9.

25. Oscai LB, Caruso RA, Wergeles AC, Palmer WK. Exercise and the cAMP system in rat adipose tissue. I. Lipid mobilization. J Appl Physiol. 1981;50:250-4.

26. Sakurai T, Endo S, Hatano D, Ogasawara J, Kizaki T, Oh-ishi S, et al. Effects of exercise training on adipogenesis of stromalvascular fraction cells in rat epididymal white adipose tissue. Acta Physiol (Oxf). 2010;200:325-38.

27. Enevoldsen LH, Stallknecht B, Fluckey JD, Galbo H. Effect of exercise training on in vivo lipolysis in intra-abdominal adipose tissue in rats. Am J Physiol Endocrinol Metab. 2000;279:E585-92.

28. Nomura S, Kawanami H, Ueda H, Kizaki T, Ohno H, Izawa T. Possible mechanisms by which adipocyte lipolysis is enhanced in exercise-trained rats. Biochem Biophys Res Commun. 2002;295: $236-42$.

29. Izawa T, Komabayashi T, Shinoda S, Suda K, Tsuboi M, Koshimizu E. Possible mechanism of regulating adenylate cyclase activity in adipocyte membranes from exercise-trained male rats. Biochem Biophys Res Commun. 1988;151:1262-8.
30. Izawa T, Mochizuki T, Komabayashi T, Suda K, Tsuboi M. $\mathrm{Ca}^{2+}$ potentiates corticotropin-induced, but not isoproterenol-induced, $\left[{ }^{3} \mathrm{H}\right]$ guanosine diphosphate release in rat adipocyte membranes. Metabolism. 1992;41:462-4.

31. Sakurai T, Takei M, Ogasawara J, Watanabe N, Sanpei M, Yoshida $M$, et al. Exercise training enhances tumor necrosis factor- $\alpha$-induced expressions of anti-apoptotic genes without alterations in caspase- 3 activity in rat epididymal adipocytes. Jpn J Physiol. 2005;55:181-8.

32. Zuk PA, Zhu M, Mizuno H, Huang J, Futrell JW, Katz AJ, et al. Multilineage cells from human adipose tissue: implications for cell-based therapies. Tissue Eng. 2001;7:211-8.

33. Smas CM, Sul HS. Pref-1, a protein containing EGF-like repeats, inhibits adipocyte differentiation. Cell. 1993;73:725-34.

34. Gregoire FM, Smas CM, Sul HS. Understanding adipocyte differentiation. Physiol Rev. 1998;78:783-809.

35. Rosen ED, Spiegelman BM. Molecular regulation of adipogenesis. Annu Rev Cell Dev Biol. 2000;16:145-71.

36. Yun Z, Maecker HL, Johnson RS, Giaccia AJ. Inhibition of PPAR $\gamma$ gene expression by the HIF-1-regulated gene DEC1/ Stra13: a mechanism for regulation of adipogenesis by hypoxia. Dev Cell. 2002;2:331-41.

37. Hatano D, Ogasawara J, Endoh S, Sakurai T, Nomura S, Kizaki $\mathrm{T}$, et al. Effect of exercise training on the density of endothelial cells in the white adipose tissue of rats. Scand J Med Sci Sports. 2011;21:e115-21.

38. Pinent M, Bladé MC, Salvadó MJ, Arola L, Ardévol A. Intracellular mediators of procyanidin-induced lipolysis in 3T3-L1 adipocytes. J Agric Food Chem. 2005;53:262-6.

39. Ogasawara J, Kitadate K, Nishioka H, Fujii H, Sakurai T, Kizaki $\mathrm{T}$, et al. Oligonol, a new lychee fruit-derived low-molecular form of polyphenol, enhances lipolysis in primary rat adipocytes through activation of the ERK1/2 pathway. Phytother Res. 2009;23:1626-33.

40. Ogasawara J, Kitadate K, Nishioka H, Fujii H, Sakurai T, Kizaki $\mathrm{T}$, et al. Oligonol, an oligomerized lychee fruit-derived polyphenol, activates the Ras/Raf-1/MEK1/2 cascade independent of the IL-6 signaling pathway in rat primary adipocytes. Biochem Biophys Res Commun. 2010;402:554-9.

41. Ogasawara J, Kitadate K, Nishioka H, Fujii H, Sakurai T, Kizaki $\mathrm{T}$, et al. Comparison of the effect of Oligonol, a new lychee fruitderived low molecular form of polyphenol, and epigallocatechin3 -gallate on lipolysis in rat primary adipocytes. Phytother Res. 2011;25:467-71.

42. Pinent M, Bladé MC, Salvadó MJ, Arola L, Hackl H, Quackenbush $\mathrm{J}$, et al. Grape-seed derived procyanidins interfere with adipogenesis of 3T3-L1 cells at the onset of differentiation. Int $\mathbf{J}$ Obes (Lond). 2005;29:934-41.

43. Wolfram S, Wang Y, Thielecke F. Anti-obesity effects of green tea: from bedside to bench. Mol Nutr Food Res. 2006;50:176-87.

44. Sakurai T, Nishioka H, Fujii H, Nakano N, Kizaki T, Radak Z, et al. Antioxidative effects of a new lychee fruit-derived polyphenol mixture, Oligonol, converted into a low-molecular form in adipocytes. Biosci Biotechnol Biochem. 2008;72:463-76.

45. Bose M, Lambert JD, Ju J, Reuhl KR, Shapses SA, Yang CS. The major green tea polyphenol, (-)-epigallocatechin-3-gallate, inhibits obesity, metabolic syndrome, and fatty liver disease in high-fat-fed mice. J Nutr. 2008;138:1677-83.

46. Shin DW, Kim SN, Lee SM, Lee W, Song MJ, Park SM. (-)-Catechin promotes adipocyte differentiation in human bone marrow mesenchymal stem cells through PPAR $\gamma$ transactivation. Biochem Pharmacol. 2009;77:125-33.

47. Shimotoyodome A, Haramizu S, Inaba M, Murase T, Tokimitsu I. Exercise and green tea extract stimulate fat oxidation and prevent obesity in mice. Med Sci Sports Exerc. 2005;37(11):1884-92. 
48. Venables MC, Hulston CJ, Cox HR, Jeukendrup AE. Green tea extract ingestion, fat oxidation, and glucose tolerance in healthy humans. Am J Clin Nutr. 2008;87(3):778-84.

49. Weisberg SP, McCann D, Desai M, Rosenbaum M, Leibel RL, Ferrante AW Jr. Obesity is associated with macrophage accumulation in adipose tissue. J Clin Invest. 2003;112:1796-808.

50. Xu H, Barnes GT, Yang Q, Tan G, Yang D, Chou CJ, et al. Chronic inflammation in fat plays a crucial role in the development of obesity-related insulin resistance. J Clin Invest. 2003; 112:1821-30.

51. Fantuzzi G. Adipose tissue, adipokines, and inflammation. J Allergy Clin Immunol. 2005;115:911-9.

52. Hotamisligil GS, Shargill NS, Spiegelman BM. Adipose expression of tumor necrosis factor- $\alpha$ : direct role in obesitylinked insulin resistance. Science. 1993;259:87-91.

53. Peraldi P, Hotamisligil GS, Buurman WA, White MF, Spiegelman BM. Tumor necrosis factor (TNF)- $\alpha$ inhibits insulin signaling through stimulation of the p55 TNF receptor and activation of sphingomyelinase. J Biol Chem. 1996;271:13018-22.

54. Plomgaard P, Bouzakri K, Krogh-Madsen R, Mittendorfer B, Zierath JR, Pedersen BK. Source tumor necrosis factor- $\alpha$ induces skeletal muscle insulin resistance in healthy human subjects via inhibition of Akt substrate 160 phosphorylation. Diabetes. 2005;54:2939-45.

55. Steinberg GR, Michell BJ, van Denderen BJ, Watt MJ, Carey AL, Fam BC, et al. Tumor necrosis factor $\alpha$-induced skeletal muscle insulin resistance involves suppression of AMP-kinase signaling. Cell Metab. 2006;4:465-74.

56. Kamei N, Tobe K, Suzuki R, Ohsugi M, Watanabe T, Kubota N, et al. Overexpression of monocyte chemoattractant protein-1 in adipose tissues causes macrophage recruitment and insulin resistance. J Biol Chem. 2006;281:26602-14.

57. Kanda H, Tateya S, Tamori Y, Kotani K, Hiasa K, Kitazawa R, et al. MCP-1 contributes to macrophage infiltration into adipose tissue, insulin resistance, and hepatic steatosis in obesity. J Clin Invest. 2006;116:1494-505.

58. Hu E, Liang P, Spiegelman BM. AdipoQ is a novel adiposespecific gene dysregulated in obesity. J Biol Chem. 1996;271: 10697-703.

59. Arita Y, Kihara S, Ouchi N, Takahashi M, Maeda K, Miyagawa J, et al. Paradoxical decrease of an adipose-specific protein, adiponectin, in obesity. Biochem Biophys Res Commun. 1999; 257:79-83.

60. Kadowaki T, Yamauchi T. Adiponectin and adiponectin receptors. Endocr Rev. 2005;26:439-51.

61. Kadowaki T, Yamauchi T, Kubota N, Hara K, Ueki K, Tobe K. Adiponectin and adiponectin receptors in insulin resistance, diabetes, and the metabolic syndrome. J Clin Invest. 2006;116: 1784-92.

62. Bradley RL, Jeon JY, Liu FF, Maratos-Flier E. Voluntary exercise improves insulin sensitivity and adipose tissue inflammation in diet-induced obese mice. Am J Physiol Endocrinol Metab. 2008;295:E586-94.

63. Vieira VJ, Valentine RJ, Wilund KR, Antao N, Baynard T, Woods JA. Effects of exercise and low-fat diet on adipose tissue inflammation and metabolic complications in obese mice. Am J Physiol Endocrinol Metab. 2009;296:E1164-71.

64. Sakurai T, Izawa T, Kizaki T, Ogasawara JE, Shirato K, Imaizumi $\mathrm{K}$, et al. Exercise training decreases expression of inflammation-related adipokines through reduction of oxidative stress in rat white adipose tissue. Biochem Biophys Res Commun. 2009;379:605-9.

65. Nara $M$, Kanda $T$, Tsukui $S$, Inukai $T$, Shimomura $Y$, Inoue $S$, et al. Running exercise increases tumor necrosis factor- $\alpha$ secreting from mesenteric fat in insulin-resistant rats. Life Sci. 1999;65:237-44.
66. Lira FS, Rosa JC, Yamashita AS, Koyama CH, Batista ML Jr, Seelaender M. Endurance training induces depot-specific changes in IL-10/TNF- $\alpha$ ratio in rat adipose tissue. Cytokine. 2009; 45:80-5.

67. Bruun JM, Helge JW, Richelsen B, Stallknecht B. Diet and exercise reduce low-grade inflammation and macrophage infiltration in adipose tissue but not in skeletal muscle in severely obese subjects. Am J Physiol Endocrinol Metab. 2006;290: E961-7.

68. Christiansen T, Paulsen SK, Bruun JM, Pedersen SB, Richelsen B. Exercise training versus diet-induced weight-loss on metabolic risk factors and inflammatory markers in obese subjects: a 12-week randomized intervention study. Am J Physiol Endocrinol Metab. 2010;298:E824-31.

69. Gollisch KS, Brandauer J, Jessen N, Toyoda T, Nayer A, Hirshman MF, et al. Effects of exercise training on subcutaneous and visceral adipose tissue in normal- and high-fat diet-fed rats. Am J Physiol Endocrinol Metab. 2009;297:E495-504.

70. Polak J, Klimcakova E, Moro C, Viguerie N, Berlan M, Hejnova J. Effect of aerobic training on plasma levels and subcutaneous abdominal adipose tissue gene expression of adiponectin, leptin, interleukin 6, and tumor necrosis factor $\alpha$ in obese women. Metabolism. 2006;55:1375-81.

71. Miyazaki S, Izawa T, Ogasawara JE, Sakurai T, Nomura S, Kizaki T, et al. Effect of exercise training on adipocyte-sizedependent expression of leptin and adiponectin. Life Sci. 2010;86:691-8.

72. Kawanishi N, Yano H, Yokogawa Y, Suzuki K. Exercise training inhibits inflammation in adipose tissue via both suppression of macrophage infiltration and acceleration of phenotypic switching from M1 to M2 macrophages in high-fat-diet-induced obese mice. Exerc Immunol Rev. 2010;16:105-18.

73. Wu LY, Juan CC, Ho LT, Hsu YP, Hwang LS. Effect of green tea supplementation on insulin sensitivity in Sprague-Dawley rats. J Agric Food Chem. 2004;52:643-8.

74. Potenza MA, Marasciulo FL, Tarquinio M, Tiravanti E, Colantuono G, Federici A. EGCG, a green tea polyphenol, improves endothelial function and insulin sensitivity, reduces blood pressure, and protects against myocardial I/R injury in SHR. Am J Physiol Endocrinol Metab. 2007;292:E1378-87.

75. Brasnyó P, Molnár GA, Mohás M, Markó L, Laczy B, Cseh J, et al. Resveratrol improves insulin sensitivity, reduces oxidative stress and activates the Akt pathway in type 2 diabetic patients. Br J Nutr. 2011;106:383-9.

76. Ikarashi N, Toda T, Okaniwa T, Ito K, Ochiai W, Sugiyama K. Anti-obesity and anti-diabetic effects of acacia polyphenol in obese diabetic KKAy mice fed high-fat diet. Evid Based Complement Alternat Med. 2011;2011:952031.

77. Suganami T, Nishida J, Ogawa Y. A paracrine loop between adipocytes and macrophages aggravates inflammatory changes: role of free fatty acids and tumor necrosis factor $\alpha$. Arterioscler Thromb Vasc Biol. 2005;25:2062-8.

78. Sakurai T, Kitadate K, Nishioka H, Fujii H, Kizaki T, Kondoh Y, et al. Oligomerized grape seed polyphenols attenuate inflammatory changes due to antioxidative properties in coculture of adipocytes and macrophages. J Nutr Biochem. 2010;21:47-54.

79. Wang A, Liu M, Liu X, Dong LQ, Glickman RD, Slaga TJ, et al. Up-regulation of adiponectin by resveratrol: the essential roles of the Akt/FOXO1 and AMP-activated protein kinase signaling pathways and DsbA-L. J Biol Chem. 2011;286:60-6.

80. Basu A, Du M, Sanchez K, Leyva MJ, Betts NM, Blevins S, et al. Green tea minimally affects biomarkers of inflammation in obese subjects with metabolic syndrome. Nutrition. 2011;27:206-13.

81. Skurk T, Alberti-Huber C, Herder C, Hauner H. Relationship between adipocyte size and adipokine expression and secretion. J Clin Endocrinol Metab. 2006;92:1023-33. 
82. Furukawa S, Fujita T, Shimabukuro M, Iwaki M, Yamada Y, Nakajima $\mathrm{Y}$, et al. Increased oxidative stress in obesity and its impact on metabolic syndrome. J Clin Invest. 2004;114:1752-61.

83. Gomez-Cabrera MC, Domenech E, Viña J. Moderate exercise is an antioxidant: upregulation of antioxidant genes by training. Free Radic Biol Med. 2008;44:126-31.
84. Ji LL. Modulation of skeletal muscle antioxidant defense by exercise: Role of redox signaling. Free Radic Biol Med. $2008 ; 44: 142-52$. 